\title{
Evaluation of Antenatal Care Screening According to the National Recommendations in Senegal
}

\author{
Aïcha Marceline Sarr ${ }^{1}$, Kamadore Toure ${ }^{2}$, Pascale Ondoa ${ }^{3,4}$, Winny Koster $^{3,5}$, \\ Adja Khady Datt-Fall ${ }^{1}$, Oulimata Diémé ${ }^{1}$, Ahmad Iyane Sow ${ }^{1}$ \\ ${ }^{1}$ Direction of Laboratories, Ministry of Health and Social Welfare, Dakar, Senegal \\ ${ }^{2}$ Department of Health Sciences, University of Thies, Thies, Senegal \\ ${ }^{3}$ Amsterdam Institute for Global Health and Development, Department of Global Health Academic Medical Center, University of \\ Amsterdam, Amsterdam, The Netherlands \\ ${ }^{4}$ African Society of Laboratory Medicine, Addis Ababa, Ethiopia \\ ${ }^{5}$ Department of Anthropology, University of Amsterdam, Amsterdam, The Netherlands
}

\section{Email address:}

aichamsarr@yahoo.fr (A. M. Sarr)

\section{To cite this article:}

Aïcha Marceline Sarr, Kamadore Toure, Pascale Ondoa, Winny Koster, Adja Khady Datt-Fall, Oulimata Diémé, Ahmad Iyane Sow. Evaluation of Antenatal Care Screening According to the National Recommendations in Senegal. Central African Journal of Public Health. Vol. 3, No. 5, 2017, pp. 73-79. doi: 10.11648/j.cajph.20170305.14

Received: August 18, 2017; Accepted: September 4, 2017; Published: September 5, 2017

\begin{abstract}
In the fight against maternal and infant mortality, Senegal has defined screening tests guidelines for antenatal care. A minimal list of six (6) tests should be requested during the first ANC visit. To contribute to the reduction of maternal mortality in Senegal, we conducted a study to evaluate, this practice in health facilities, taking into account the national guidelines in order to formulate recommendations. The study was conducted in 16 health peripheral facilities. We collected data on tests requested, pregnant age, pregnancy age, gestity, midwives monthly salary, midwives number, type of structure (Hospital and Health Center), regions (capital and others), and the availability of guidelines. The quantitative data were collected from 1692 pregnant women, 61 midwives and 16 financial managers with appropriate tools, from February 2013 to July 2014. Data were entered in Microsoft Excel versions 2013 and Open Clinica and then exploited and analyzed in SPSS version 20. Univariate and bivariate analyses were computed. Only $49.2 \%$ of pregnant women have received the 6 recommended tests. Requested tests were Syphilis (96\%), Blood group (90\%), Emmel Test for sickle cell anemia (90\%), Hemogram (81\%), HIV serology (78\%) and Protein urine test $(67 \%)$. Factors associated with guidelines adherence were: (i) first antenatal visit ( $\mathrm{p}<0.001)$, (ii) midwives monthly salary $(\mathrm{R}=-0,232)$, and (iii) regions type $(\mathrm{p}<0.001)$. It is important to take into account these results. For a better antenatal care, we recommend to train and motivate midwives on the national guidelines, in Senegal, and to sensitize childbearing about the importance of tests.
\end{abstract}

Keywords: Guidelines, Maternal Screening Tests, Antenatal Care, Maternal Mortality, Senegal

\section{Introduction}

Maternal mortality is defined as 'the death of a woman while pregnant or within 42 days of termination of pregnancy, irrespective of the cause of death', according to WHO [1]. According to WHO, every day, women die in the world with disparity through continents. In developing countries, in 2015, the rate was 239 per 100,000 births, compared to 12 per 100,000 in developed countries. The majority of maternal deaths $(99 \%)$ occur in developing countries, more than half in sub-Saharan Africa and almost one-third in South Asia [1].
Nigeria and India account for more than one-third of all maternal deaths worldwide, in 2015, with 58000 (19\%) and $45000(15 \%)$ respectively [2]. In Senegal, the maternal death rate was estimated in 2015 to 392 per 100,000 live births [3]. Despite all efforts to reduce maternal mortality, the Millenium Development Goals 4 targeting 133 out of 100,000 were not achieved. The goal of reducing the burden of maternal and infant morbidity and mortality was already highlighted in 1978 through the Alma Ata Declaration loading the Primary Health Care strategy [4]. This strategy was adopted by governments and materialized through the 
development of national policies. The first National Health Policy (PNS) document has been writing in 1989, followed by the two national health development plans (PNDS), covering the periods 1998-2008 and 2009-2018. The PNP (Policies, Norms and Protocols) was developed as part of the implementation of the PNDS, giving the strategic orientations in terms of overall maternal care, including tests guidelines [5]. However, all these policies were implemented and operationalized in the health system, maternal mortality is still high in the African continent in general, and Senegal in particular. Causes of maternal deaths have been already established. Direct causes are dominated by hemorrhage $(31.3 \%)$ and preeclampsia/ecclampsia $(26.4 \%)$, while nonobstetric causes are severe anemia $(36.3 \%)$ and malaria (21.4\%). Complications related to HIV / AIDS (2.8\%) and viral hepatitis B $(1.6 \%)$ were the two least frequent causes [6]. Death of maternal related causes should be the action lever for effective policy for the management of maternal mortality [7]. Senegal has adopted laboratory testing guidelines especially for first antenatal care, whatever the pregnancy age, to protect the mother-child couple from pathologies that may affect their health [6]. It is composed of 6 tests: Blood Group and Rhesus Factor (BG/RH), Hemogram/ Blood Count (BC), Emmel Test (TE) to screen for sickle cell anemia, Syphilitic serology, HIV serology (by the provider's initiative), and Protein urine test.

The comprehensive review of the literature has presented a qualitative study [8], and quantitative researches for laboratory examination in Sierra Leone and Pakistan [9-10], related to guidelines tests requested. Others studies have focused on some individual tests in the context of Prevention of Mother-to-Child Transmission (PMTCT). These include HIV screening testing, hepatitis B and syphilis [11-15]. Their evaluation was done on an individual form. Another author focused on some tests screening including Hemogram, Blood group and Rhesus factor, and Syphilitic serology [16]. For all these studies, authors focused on tests made instead of tests requested. The integration of HIV and syphilis in Elimination of mother-to-child transmission of HIV and Syphilis (EMTCT) program may be the reason why many studies focused on these two tests $[17,18]$.

In addition, Demographic and Household Surveys (DHS) usually measure uptake of urine and blood sampling - not specifying whether and which tests were carried out on the specimens, estimating at $87 \%$ for urine and $82 \%$ for blood collection [19]. The non-adherence with requests guidelines may be a missed opportunity to improve maternal health. In the fight against maternal mortality, we conducted this study to evaluate the antenatal care screening tests requests according to the national guidelines in Senegal.

\section{Method}

\subsection{Context of the Study}

In the context of the fight against maternal mortality in Senegal, we have carried out this work in order to evaluate the ANC midwives tests requests among pregnant women receiving the first $\mathrm{ANC}$ visit (ANC1).

\subsection{Study Sites}

The study was conducted in 10 regions (out of 14 in the country), precisely in 16 peripheral structures, including 12 Health Centers (HC) and 4 Hospitals (HOSP). These are the HC of Camberene (CA), Dagana (DA), Diamniadio (DI), Gaspard Kamara (GK), Gossas (GO), HLM (HLM), Kasnack (KA), Khombole (KH), Kedougou (KE), Mbacké (MBA), Tambacounda (TA), Ziguinchor (ZI), HOSP of Mbour (MBO), Roi Baudouin (RB), Richard Toll (RT) and Sedhiou (SE).

\subsection{Study Population}

The study population included 16 financial managers, 61 midwives, and 1692 pregnant women in their first ANC visit (ANC1).

\subsection{Type of Research}

It was a quantitative research, where data collection was carried out in a standardized way, using appropriate tools for each target.

\subsection{Variables Studied}

The variables studied from midwives were: tests requested, midwives number, monthly salary (state and no state), availability of national guidelines in health facilities. Guidelines adherence was also evaluated. It was considered normal when all six tests were requested by midwives, abnormal when the number of test requested was less than six. The variables studied from pregnant women were: age, gestity, period of the first antenatal visit, type of structures frequented (Health center or Hospital), type of regions (Capital Dakar and others regions).

\subsection{Data Collection}

\subsubsection{Tools}

Three checklists, previously tested, in a pilot study, in two structures in the Dakar region (a health center and an hospital), corrected and then validated, were used as collection tools. The questions were either opened, closed, or observational. Each tool was especially developed for the purpose of the study, for each target. The first tool, called the 'study card' simulated the health booklet and reproduced all pregnant woman circuit, from the tests requested, by midwives, to the medical care based on laboratory results (pathological or not). It contains information on the sociodemographic profile of pregnant women and tests requested. The finance tool was used to collect monthly salaries and the number of midwives. The ANC2 tool contained information about the availability of guidelines documentation.

\subsubsection{Data Collection Process}

Midwives were first trained about the way to fill the 'study card'. They filled during ANC visits socio-demographic information and ticking themselves boxes related to tests 
requested. The minimum quota required was 100 pregnant women per health facility. As soon as the quota was reached, the cards were sent to the supervisor of the research team. Finance and ANC questionnaires were directly applied to the targets, by the supervisor of the research team, assisted by two research assistants. The quality control and the validation of the collected data were carried out daily. The stay per structure was 5 working days. The data collection has been conducted during one year-period, from February 2013 to July 2014.

The methodological approach adopted was an exhaustive review of the documents published in PubMed, Scholar and Public Health, and the gray literature, including various national policy documents, standards and national strategy procedures, followed by an active analysis. Human resources assessment was based on the national document, called Policies, Norms and Protocols (PNP) and the health map, which gives an average of 4 midwives for health centers and 6 for the hospital levels. Salaries were assessed on the basis of the table of Senegalese salary categories and salary scales. Midwives are from Class III, category 3.1, which is subdivided into eight (8) steps, in application of Decree 2016/404 on the Staff Regulations of the Public Health Hospitals. Community staff salaries were compared to the national document. For each structure, the ratio of the average salary to the norm was determined. These variables were then correlated with the rate of guidelines adherence.

\subsubsection{Data Entry and Analysis}

Data were entered into Open Clinica. After the entry, quality control was carried on a random sample of $10 \%$. After validation, all data were exported and analyzed using SPSS-20.0 version for Windows. Univariate analysis was done allowing computation of frequencies, percentages, means (with standard deviation) and ratios (for health resources). Bivariate analysis were done to compare percentages using the Chi Square. We computed also correlations between quantitative data using the Pearson test. Results were considered statistically significant with $\mathrm{P}$ value $<0.05$ and $\mathrm{R}<0.5$.

Ethical Considerations

The protocol was approved by the National Ethics Committee of Senegal (CNES) (SEN13 / 09).

\section{Results}

\subsection{Characteristics of the Population}

The study involved 1692 pregnant women, who had an average age of $25.25 \pm 6.19$ years during the first ANC visit. The majority (93.79\%) had childbearing age (15-47 years). Women visiting health facility for their first antenatal visit was highest $(53.96 \%)$ among others. The majority of pregnant women had their first ANC visit in health centers $(75.65 \%, \mathrm{n}=1280)$. They were mainly multigest $(65.54 \%, \mathrm{n}$ $=1109)$. A total of 61 midwives had been interviewed, one third was a state midwifery grade, awarded after the national competition, held annually. No midwive was trained on the use of the guidelines and guidelines were only available in one $(1 / 16)$ health facility (Table 1$)$.

Table 1. Characteristics of the study population.

\begin{tabular}{|c|c|c|}
\hline Variables & $\mathbf{n}$ & Percentage (\%) \\
\hline Pregnant women & 1692 & \\
\hline Mean age: 25.25 years \pm 6.19 & & \\
\hline Extreme ages: $15-47$ years & & \\
\hline Age ranges & & \\
\hline $15-47$ years & 1587 & 93.79 \\
\hline$<15$ years & 31 & 6.21 \\
\hline \multicolumn{3}{|l|}{ Period of first ANC visit } \\
\hline First trimester & 906 & 54 \\
\hline Second trimester & 619 & 37 \\
\hline Third trimester & 124 & 7 \\
\hline$>$ Third trimester & 30 & 2 \\
\hline \multicolumn{3}{|l|}{ Site of visit } \\
\hline Health center & 1280 & 75.65 \\
\hline Hospital & 412 & 24.35 \\
\hline \multicolumn{3}{|l|}{ Gestity } \\
\hline Primigest & 583 & 34.83 \\
\hline Multigest & 1109 & 65.54 \\
\hline $\begin{array}{l}\text { Avalailability of national } \\
\text { guidelines }\end{array}$ & $1 / 16$ & \\
\hline Midwives & 61 & \\
\hline \multicolumn{3}{|l|}{ Type of Midwife } \\
\hline No state & 24 & 39 \\
\hline State & 37 & 74 \\
\hline \multicolumn{3}{|l|}{ Monthly Salary in \$US } \\
\hline State midwives (mean $\pm \mathrm{SD}$ ) & $483.35 \pm 76.72$ & \\
\hline No state midwives (mean $\pm \mathrm{SD}$ ) & $175.54 \pm 97.91$ & \\
\hline Mean $($ mean $\pm \mathrm{SD})$ & $342.33 \pm 72.10$ & \\
\hline \multicolumn{3}{|l|}{ Number of midwife } \\
\hline Ratio for Health Centers & 0.96 & \\
\hline Ratio for Hospital & 1.12 & \\
\hline State $($ Mean \pm SD) & $2.31 \pm 0.94$ & \\
\hline No State (Mean $\pm \mathrm{SD}$ ) & $1.50 \pm 0.96$ & \\
\hline
\end{tabular}

\subsection{Overall Results of ANC Tests}

A total of $49.2 \%$ of pregnant women received the full range of 6 recommended tests. The most requested tests were Syphilis serology (96\%), Blood group (90\%), Emmel test (90\%), Hemogram (81\%), HIV serology (78\%) and Protein urine test $(67 \%)$ (Table 2). None of the sixteen health facilities were fully compliant $(100 \%)$ with national guidelines. Only half of the facilities had more than $50 \%$ of adherence rates (Ziguinchor, Roi Baudouin, Gossas, Gaspard Kamara, Kedougou, Khombole, Mbacke, Kasnack) (Table 2).

Table 2. Overall results of ANC tests.

\begin{tabular}{lll}
\hline Variables & Frequency & Percentage (\%) \\
\hline Frequency of tests & & \\
6 tests & 834 & 49.2 \\
5 tests & 378 & 22.4 \\
4 tests & 249 & 14.7 \\
3 tests & 175 & 10.4 \\
2 tests & 45 & 2.7 \\
1 test & 11 & 0.7 \\
Total & 1692 & 100 \\
Type of tests & & \\
Syphilis serology & 1624 & 96 \\
Emmel test & 1522 & 90 \\
Blood group, Rhesus factor & 1372 & 90 \\
Hemogram & 1528 & 81 \\
\hline
\end{tabular}




\begin{tabular}{lll}
\hline Variables & Frequency & Percentage (\%) \\
\hline HIV serology & 1319 & 52 \\
Protein urine test & 1139 & 67 \\
Completed test among Health facilities & & \\
Ziguinchor & $71 / 96$ & 74 \\
Roi Baudouin & $74 / 105$ & 70.48 \\
Gossas & $69 / 100$ & 69 \\
Gaspard Kamara & $74 / 113$ & 65.49 \\
Kédougou & $64 / 102$ & 62.75 \\
Khombol & $66 / 104$ & 63.46 \\
Mbacké & $65 / 103$ & 63.11 \\
Kasnack & $61 / 98$ & 62.24 \\
Diamniadio & $55 / 93$ & 59.14 \\
Mbour & $59 / 114$ & 51.75 \\
HLM & $48 / 105$ & 45.71 \\
\hline
\end{tabular}

\begin{tabular}{lll}
\hline Variables & Frequency & Percentage (\%) \\
\hline Sedhiou & $43 / 99$ & 43.43 \\
Camberene & $39 / 107$ & 36.45 \\
Richard Toll & $44 / 125$ & 34.2 \\
Tambacounda & $5 / 127$ & 3.94 \\
Dagana & $0 / 98$ & 0 \\
\hline
\end{tabular}

\subsection{Bivariate Results}

In the bivariate analysis, only first antenatal visit $(\mathrm{p}$ $<0.001)$, region type $(\mathrm{p}<0.001)$ and midwife salary $(\mathrm{R}=-0,232)$ were associated with guidelines adherence. Indeed, the earlier the ANC, the most respected were the guidelines (Table 3).

Table 3. Variability of guidelines adherence according to women's characteristics and health facilities level.

\begin{tabular}{|c|c|c|c|c|}
\hline \multirow{2}{*}{ VARIABLES } & \multicolumn{2}{|c|}{ GUIDELINES ADHERENCE } & \multirow{2}{*}{ TOTAL } & \multirow{2}{*}{ p-value } \\
\hline & YES & NO & & \\
\hline Period of ANC1 & & & & $<0,001$ \\
\hline First trimester & $505(55.74 \%)$ & $401(45.74 \%)$ & $906(100 \%)$ & \\
\hline Second trimester & $279(45.07 \%)$ & $340(54.93 \%)$ & $619(100 \%)$ & \\
\hline Third trimester & $38(30.65 \%)$ & $86(69.35 \%)$ & $124(100 \%)$ & \\
\hline$>$ Third trimester & $7(23.33 \%)$ & $23(76.67 \%)$ & $30(100 \%)$ & \\
\hline Gestity & & & & 0.658 \\
\hline Primigest & $291(50.17 \%)$ & 289 (49.83\%) & $580(100 \%)$ & \\
\hline Multigest & $532(49.03 \%)$ & $553(50.96 \%)$ & $1084(100 \%)$ & \\
\hline Pregnant age & & & & 0.264 \\
\hline$<15$ years & $14(45.16 \%)$ & $17(54.84 \%)$ & $31(100 \%)$ & \\
\hline$>15$ years & $789(49.71 \%)$ & $798(50.28 \%)$ & $1587(100 \%)$ & \\
\hline Total & $832(46.44 \%)$ & $858(52.56 \%)$ & $1690(100 \%)$ & \\
\hline \multicolumn{5}{|l|}{ Type of structure } \\
\hline Health Center & $617(49.52 \%)$ & $629(50.48 \%)$ & $1246(100 \%)$ & 0.64 \\
\hline Hospital 1 & $215(48.42 \%)$ & $229(51.58 \%)$ & $444(100 \%)$ & \\
\hline Regions & & & & \\
\hline Dakar & $291(55.45 \%)$ & $234(44.55 \%)$ & $525(100 \%)$ & $<0.001$ \\
\hline Others & $41(46.91 \%)$ & $626(53.08 \%)$ & $1167(100 \%)$ & \\
\hline
\end{tabular}

\section{Discussion}

\subsection{Guidelines Are Not Respected}

Our study shows that the gap between requests guidelines and practice is a reality. In 2012, Emergency Obstetric Care Surveys had, however, identified the causes of maternal deaths in Senegal. Studies have already highlighted the important role of prenatal screening for the prevention of maternal mortality and morbidity. These include proteinuria (PU) for the risk of pre-eclampsia, and screening for HIV and syphilis to prevent mother-to-child vertical transmission [20-21]. Anaemia, during pregnancy increases the risk of dying from hemorrhage, stillbirth, low birth weight (LBW), prematurity, and neonatal death [22]. Guidelines adherence were observed on only $49.2 \%$ of pregnant women. This result showed that completed screening tests is not always a reflex among health provider. In the district of Bamako (Mali), the proportion of women (169) who made usual screening test (blood group, syphilis serology and Emmel test) was 47,9 \% during a survey (81/169) [16]. In Ghana, non-adherence to guidelines is almost general, throughout, all ANC steps (95\% CI: 41.8-54.2\%) [23]. In Paskistan, only $82.4 \%$ participants were screened for blood group and haemoglobin, $79.1 \%$ for blood glucose and hepatitis, and $0 \%$ for HIV and syphilis [9]. In Sierra Leone, less than a third of women were screened for haemoglobin estimation, albumin in urine and syphilis (10-28\%), compared to an HIV test $(50 \%)(10-28 \%)[10]$. In the United States, complete adherence to screening test was $54.5 \%$ [14]. Otherwise, in our study, guidelines were only present in one over 16 health facilities. This situation was also observed during a study conducted in Tanzania where National HIV guidelines were only available in one (1) structure. Guidelines availability is very importante in all health facilities, to allow health providers to be familiar with them. On the other hand, it is necessary to train midwives and doctors for a better use of these protocols and guidelines [24]. Providers also were not been involved in the revisions and guidelines implementation [11]. These results also confirm the findings of other studies, regarding the participation of local users in the design of standards and protocols which would facilitate their implementation. Implementation of the protocols requires the commitment of the providers so that they can better understand the issues associated with adherence [25-26]. The lack of dissemination of guidelines and protocols, associated with the absence of midwives commitment during the developmental phase seems to be the real reasons for non-adherence observed [27-28]. Antenatal care visits allow to sensitize about signs of 
danger, early detection and treatment of maternal and fetal risk situations to ensure safe motherhood [29]. For that, the laboratory plays a central role, helping for the diagnosis of pathologies to prevent mother-child couple. Thus, the nonadherence to antenatal guidelines requests, during the first ANC visit, demonstrates the clear underutilization of the laboratory. It is a missed opportunity to prevent mothers and child against diseases responsible for morbidity and mortality. Paradoxically, despite the low guidelines adherence level, in a systematic search for evidence-based guidelines, screening interventions were the most common practices. They include screening for syphilis, HIV, anaemia and pre-eclampsia and routine $\mathrm{ABO}, \mathrm{RhD}$ testing [30].

\subsection{Determinants of Non-adherence with Guidelines}

In the bivariate analysis, only first antenatal visit ( $\mathrm{p}$ $<0.001)$, region type $(\mathrm{p}<0.001)$ and midwife salary $(\mathrm{R}=-0,232)$ were associated with guidelines adherence. Indeed, the earlier the ANC, the most respected were the guidelines. The arrival at $\mathrm{ANC1}$ is a condition for ANC tests request and can impact on guidelines adherence. In fact, the later it is, less the guidelines are respected with a rate varying from $55.74 \%$ to $23.33 \%$, from the first to third trimester in our study. Unfortunately in Senegal, doing an ANC visit in the first trimester after pregnancy is not so common during pregnancy. A survey conducted in 2014 showed that only $59 \%$ of women did their visit in less than 4 months [DHS survey (2014)]. The first ANC visit must therefore be done relatively early in pregnancy, to allow a fourth ANC visit as recommended by the Ministry of Health [5]. Moreover, obviously, ANC1 delay is a major factor limiting the appropriate monitoring of pregnancy [31]. Some midwives have reported referring to the health records of previous pregnancies to check tests whose results have been already known and irreversible, as the sickle cell anemia (Emmel test) and blood grouping. Others prefer sparing women to unnecessary expenses. For the last, there is another reason: "more the pregnancy is advanced, less tests are requested, because pregnant women will no longer have time to complete the set of tests". Sometimes, tests are made at delivery in emergency. Midwives seem to override the pre-established guidelines, confirming the conclusions of others authors, characterizing them as laboratory's gatekeepers. The concept no test requests, no laboratory, is then understandable [8]. The gap is often due to the routine behaviour of midwives who follow practical norms that are often distinct from official norms [32]. Despite all these conditions, the association between gestity and guidelines adherence $(p=0.658)$ was not significant. Others studies have focused on parity and previous pregnancies with complications. Our findings are not in compliance with Ghana's study, where a multivariate analysis has shown that it is in the multiparous that compliance is most observed [OR $=5.43$ (1.69-17.44), $\mathrm{p}$ $<0.01$ ] [33]. The bivariate analysis has also shown the regional disparity $(\mathrm{p}<0.001)$ regarding guidelines adherence. In fact, the others regions were significantly disadvantaged compared to Dakar, the capital. Dakar is most advantaged in terms of health facilities and health personnel compared to other regions. These findings suggest the need to be corrected further, because regional inequalities affect maternal mortality, as already reported [34]. However, our findings showed that regardless where the ANC1 was performed (Health Center or Hospital), adherence to protocols was invariant $(\mathrm{p}=0.640)$. This is the case also in Ivory Coast [14]. However, according to Amoakoh-Coleman et al., overall ANC guidelines are more respected among the women observed in the polyclinics $(51.9 \%)$ compared to those seen in public hospitals (47.6\%) and the health center $(33.8 \%)$ [23]. Another feature is the deficit of midwives in the majority of the health facilities in our study $(9 / 16$ with a ratio $<1)$ compared to the human resources guidelines. This human resource gap did not affect guidelines adherence. These results confirm the findings of other studies, defending the need to build workforce capacity (quality), it is more important than quantity $[30,35]$. On the other hand, guidelines adherence seemed to be strongly correlated to monthly salary of the midwives. The higher the salary, more guidelines adherence was observed, mainly for midwives recruited by the government (mean $=483.35 \pm 76.72$ USD; $\mathrm{R}=-0.023$ ). These ones, received, in addition to their salaries, incentives, compared to contractual and community colleagues, recruited by the structures themselves or with contract (Mean $=175.54 \pm 97.91$ USD; $\mathrm{R}=0.006$ ). These results suggest the importance of financial motivation on the quality of midwifery services. This situation has although motivated, the introduction of the concept of the Resultsbased Financing Policy (RBF), focusing on maternal and infant mortality. In Rwanda, it allowed an increase of $15.7 \%$ (95\% CI $0 \cdot 026-0 \cdot 289)$ on the quality of services [36-37]. In Senegal, the immediate results are certainly probative, but it is important to conduct further researches, in order to identify in the medium and long term the effects on the utilization of maternal health care, results and the quality of services [38-39]. However, motivation with ongoing training and mentoring for women's health is also important for midwives [40]. Guidelines adherence is important to ensure uniformity and quality of antenatal care and to maintain quality service provision to patients based on their specific needs. Also, complete adherence to the guidelines decreased risk of any neonatal and delivery complication [41].

As all studies, this one has several limitations. One of the limitations of the study was the sample size of the health facilities, which doesn't ensure the national coverage, for financial reasons.

Despite the 5 days data collection, some data were missed, which could have an impact on the validity of the results obtained (parity, experience of the midwife, training of the midwives on the PNP guidelines). However, there results give us an overview of the expected situation, regarding the adherence to PNP guidelines.

\section{Conclusion}

Study findings revealed that it exists a gap between 
national recommendations and practice in terms of guidelines screening. Only less than half pregnant women received the full range of recommended tests. The most requested tests were Syphilis serology, Blood group, Emmel test, Hemogram, HIV serology and Protein urine test. However, no health personnel was trained and guidelines available in only one health facility. The determinants associated with nonadherence with guidelines were the pregnancy age, midwives monthly salary and regional disparity.

For improving guidelines adherence, it is necessary to sensitize women of childbearing age about ANC visits and to train and motivate midwives. Guidelines availability is also very important in all facilities. So, it urges to make them available in health facilities for their use regarding Policies, Norms and Protocols, outlined by the Senegalese Ministry of Health.

\section{Conflict of Interest Statement}

The authors declare that they have no conflicts of interest.

\section{Acknowledgements}

This work was supported by the Netherland Organization for Scientific Research, Science for Global Development (NWO/WOTRO), grant W07.4.203.00, in SOCIALAB project.

We are grateful to Anja Van't Hoog and Mafall Ka for their contribution to statistical analysis, the staff of the Direction of Laboratories in Senegal, for their active participation to tools reviews and pilot phase.

\section{Authors' Contributions}

AMS: was the scientific senior researcher, in charge of biomedical compound of the project (SOCIALAB). First author, conducted the data collection, analysis and developed the draft manuscript for publication. AIS: (University Cheikh Anta Diop-Dakar, the Director of the Laboratories in Senegal), co-Principal Investigator. PO (Amsterdam Institute of Global Health of Development): was the Principal Investigator. WK (University of Amsterdam): was the scientific senior researcher, in charge of anthropological compound of the project. OD: was an assistant researcher administered financial questionnaire and electronic data entry. AKDF: was an assistant researcher, administered midwives questionnaire and electronic data entry. KT (University of Thies, Thies-Senegal), critically revised the draft for important intellectual content, revision and final approval of this article. All authors critically revised the manuscript.

\section{References}

[1] WHO. Maternal Mortality: Fact sheet $\mathrm{N}^{\circ} 348$, updated November 2016.

[2] INED. Les Mémos de la Démo, Fiche pédagogique «La mortalité maternelle dans le monde» 2016.
[3] WHO. Maternal and perinatal country profile Senegal, 2015. www.who.int/maternal_child_adolescent/epidemiology/profil es/maternal/sen.pdf-accessed 12.01.2017).

[4] WHO. Declaration of Alma-Ata International Conference on Primary Health Care, Alma-Ata, USSR, 6-12 September 1978. WHO, Geneva, Switzerland.

[5] Ministère de la Santé et de l'Action Sociale du Sénégal (MSAS). Politiques, Normes et Protocoles de la SR, 2007.

[6] Ministère de la Santé et de l'Action Sociale du Sénégal (MSAS). Enquête SONU (Soins Obstétricaux et Néonataux d'Urgence), 2012.

[7] Say L, Chou D, Gemmill A, Tunçalp Ö, Moller AB, Daniels J, Gülmezoglu AM, Temmerman M, Alkema L. Global causes of maternal death: A WHO systematic analysis. Lancet Glob Health. 2014; 2(6):e323-33.

[8] Koster W, Ondoa P, Sarr AM, Sow AI, Schultsz C, Sakande J, Diallo S, Pool R. Barriers to uptake of antenatal screening tests in Senegal. SSM-Population Health. 2016; 784-792.

[9] Ashraf F, Thaver IH, Imtiaz F, Ayub A. Quality assessment of focused antenatal care service. Delivery in tertiary care health facility. J Ayub Med Coll Abbottabad. 2017; 29(2):219-224.

[10] Koroma MK, Kamara SS, Bangura EA, Kamara MA, Lokossou V, Keita N. The quality of free antenatal and delivery services in Northern Sierra Leone. Health Research Policy and Systems 2017; 15(Suppl 1):13-19.

[11] Mwangome MN, Geubbels E, Wringe A, Todd J, Klatser P, Dieleman M. A qualitative study of the determinants of HIV guidelines implementation in two south-eastern districts of Tanzania. Health Policy Plan. 2017; 32(6):825-834.

[12] Obermeyer CM, Neuman M, Hardon A, Desclaux A, Wanyenze R, Ky-Zerbo O, Cherutich P, Namakhoma I. Socioeconomic determinants of HIV testing and counselling: a comparative study in four African countries. Trop Med Int Health. 2013;18(9):1110-1118.

[13] Nsom M. D. S. Déterminants de la pratique du test de dépistage du VIH Sida chez la femme enceinte au Cameroun. Thèse pour l'obtention du Diplôme d'Etudes Supérieures Spécialisées (DESSD), Université de Cameroun, 27e promotion (2005-2007).

[14] Bagny A, Bathaix Yao F, Bangoura D, Kouame DH, Kacou Ya Kissi-Anzouan H, De O, Diallo K, Lawson-Ananisoh LM, Mahassadi KA, Attia Koffi A, Ndri-Yoman T. Evaluation of midwives' practices for the prevention of mother-to-child transmission of hepatitis B in Abidjan (Ivory Coast). Médecine et Santé Tropicales. 2015; (25): 206-209.

[15] Bocoum FY, Kouanda, S Zarowsky C. Barriers to antenatal syphilis screening in Burkina Faso. Pan African Medical Journal. 2014; 17(Supp 1)12: 71-75.

[16] Sakho M. Les dernières consultations prénatales dans le district de Bamako: analyse critique des procédures, résultats et perspectives d'amélioration. Bull Soc Path Exo 2000; 93 (5):331-6.

[17] Taylor M, Newman L, Ishikawa N, Laverty M, Hayashi C, Ghidinelli M, et al. Elimination of mother-to-child transmission of HIV and Syphilis (EMTCT): Process, progress, and program integration. PLoS Med. 2017 14(6): e1002329. https:// doi.org/10.1371/journal.pmed.1002329. 
[18] WHO. Global Guidance on Criteria and Processes for Validation: Elimination of Mother-to-Child Transmission of HIV and Syphilis. WHO, Geneva, 2014. ISBN 978924 1505888

[19] République du Sénégal. Enquête Démographique et de Santé Continue au Sénégal - EDS continue 2014.

[20] Carroli G, Rooney C, Villar J. How effective is antenatal care in preventing maternal mortality and serieus morbidity? An overview of the evidence. Pediatric and Perinatal Epidemiology. 2001. 14(1): 1-42.

[21] Di Mario S, Basevi V, Daya L, Magnano L, Magrini N. What is the effectiveness of antenatal care? (Supplement) Copenhagen, WHO Regional Office for Europe (Health Evidence Network report), 2005. http://www.euro.who.int/Document/E87997.pdf, accessed 02 Aout 2017.

[22] Lincetto O, Mothebesoane-Anoh S, Gomez P, Munjanja S. Antenatal care In: Lawn J, Kerber K, editors. Opportunities for Africa's Newborns: practical data, policy and programmatic support for newborn care in Africa. Geneva: World Health Organization. 2006:51-62.

[23] Amoakoh-Coleman M, Akua Agyepong I, Kayode GA, Grobbee DE, K Klipstein-Grobusch K, Ansah EK. Public health facility resource availability and provider adherence to first antenatal guidelines in a low resource setting in Accra, Ghana. BMC Health Serv Res. 2016; 16: 505.

[24] Patience NTS, Sibiya MN, Gwele NS. Evidence of application of the Basic Antenatal Care principles of good care and guidelines in pregnant women's antenatal care records. Afr J Prm Health Care Fam Med. 2016; 8(2), a1016. http://dx.doi. org/10.4102/phcfm. v8i2.1016.

[25] Burstin HR, Conn A, Setnik G, Rucker DW, Cleary PD, O'Neil AC, Orav EJ, Sox CM, Brennan T. Benchmarking and quality improvement: the Harvard Emergency Department Quality Study. The American Journal of Medicine 1999. 107(5):437-49.

[26] Rowe AK, de Savigny D, Lanata CF, Victora CG. How can we achieve and maintain high-quality performance of health workers in low-resource settings? The Lancet. 2005 (366): $1026-35$.

[27] Grilli R, Lomas J. Evaluating the Message: The Relationship between Compliance Rate and the Subject of a Practice Guideline. Med Care. 1994; 32(3):202-13.

[28] Gagliardi AR, Brouwers MC, Palda VA, Lemieux-Charles L, Grimshaw JM. How can we improve guideline use? A conceptual framework of implementability. Implement Sci. 2011; 6: 26. Implement Sci. 2011; 6: 26.

[29] Cabana MD, Rand CS, Powe NR, Wu AW, Wilson MH, Abboud PA, et al. Why don't physicians follow clinical practice guidelines? A framework for improvement. JAMA 1999; 282(15):1458-65.
[30] Edgardo A, Monica C, Virginia D, Özge T, Metin GA. Antenatal care for healthy pregnant women: a mapping of interventions from existing guidelines to inform the development of new WHO guidance on antenatal care. BJOG 2016; 123: 519-528.

[31] N'Diaye P, Dia AT, Diediou A, Dieye E. H. L., Dione DA. Déterminants socioculturels du retard de la 1re Consultation prénatale dans un district sanitaire au Sénégal. Santé Publique. 2005; 4(17): 531 - 538.

[32] de Sardan J-PO, Diarra A, M Moha M. Travelling models and the challenge of pragmatic contexts and practical norms: the case of maternal health Health Research Policy and Systems 2017, 15(Suppl 1):60. DOI 10.1186/s12961-017-0213-9.

[33] Amoakoh-Coleman M, Agyepong IA, Zuithoff NPA, Kayode GA, Grobbee DE, Klipstein-Grobusch K, et al. Client Factors Affect Provider Adherence to Clinical Guidelines during First Antenatal Care. PLoS One. 2016;11:e0157542.

[34] Tripathi V, Singh R. Regional differences in usage of antenatal care and safe delivery services in Indonesia: findings from a nationally representative survey. BMJ Open. 2017;7:e13408.

[35] Fauveau V, Sherratt DR, de Bernis L. Human resources for maternal health: multi-purpose or specialists? Human Resources for Health. 2008; 6:21.

[36] Basinga P, Gertler JP, Binagwaho A, Soucat LB, Sturdy J, Vermeersch CMJ. Effect on maternal and child health services in Rwanda of payment to primary health-care providers for performance: an impact evaluation. Lancet. 2011; 377: 142128.

[37] Morgan L, Stanton ME, Higgs ES, Balster RL, Bellows BW, Brandes N, Alison Comfort AB, Eichler R, Glassman A, Hatt LE, Conlon CM, Koblinsky M. Financial Incentives and Maternal Health: Where Do We Go from Here? J. Health Popul. Nutr. 2013:31(4 Suppl 2): S8-S22.

[38] Ministère de la Santé et de l'Action Sociale. Manuel de procédures du projet pilote de financement basé sur les résultats (FBR) dans le secteur de la santé au Sénégal, 2ème version Sept, 2013.

[39] Ministère de la Santé et de l'Action Sociale. Plan d'accélération des interventions pour la survie de l'enfant, 2013-2015.

[40] Temmerman M, Khosla R, Laski L, Mathews Z, Say L. Women and Health Working Group for the Global Strategy for Women's, Children's and Adolescents' Health. Women's health priorities and interventions. BMJ. 2015; (9)14;351:h4147.doi:10.1136/ bmj.h4147.

[41] Amoakoh-Coleman M, Klipstein-Grobusch K, Akua Agyepong I, Kayode GA, Grobbee DE, and Ansah EK. Provider adherence to first antenatal care guidelines and risk of pregnancy complications in public sector facilities: a Ghanaian cohort study. BMC Pregnancy Childbirth. 2016; 16: 369.doi: 10.1186/s12884-016-1167-6. 